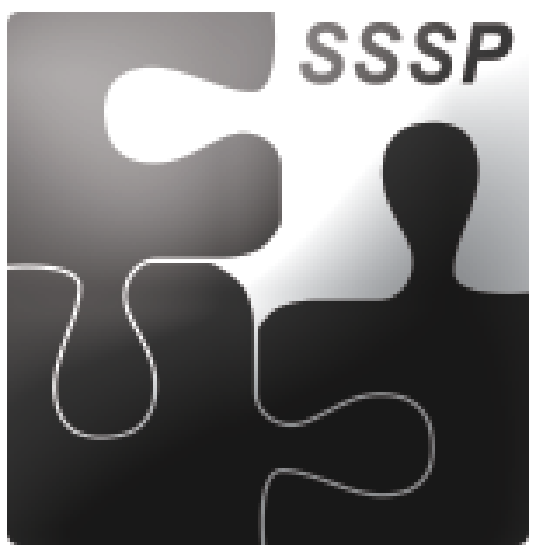

Ideology and the Clamshell Identity: Organizational Dilemmas in the Anti-Nuclear Power Movement

Author(s): Gary L. Downey

Source: Social Problems, Vol. 33, No. 5 (Jun., 1986), pp. 357-373

Published by: University of California Press on behalf of the Society for the Study of Social Problems

Stable URL: http://www.jstor.org/stable/800656

Accessed: 19/02/2014 09:16

Your use of the JSTOR archive indicates your acceptance of the Terms \& Conditions of Use, available at http://www.jstor.org/page/info/about/policies/terms.jsp

JSTOR is a not-for-profit service that helps scholars, researchers, and students discover, use, and build upon a wide range of content in a trusted digital archive. We use information technology and tools to increase productivity and facilitate new forms of scholarship. For more information about JSTOR, please contact support@jstor.org. 


\title{
IDEOLOGY AND THE CLAMSHELL IDENTITY: ORGANIZATIONAL DILEMMAS IN THE ANTI-NUCLEAR POWER MOVEMENT*
}

\author{
GARY L. DOWNEY \\ Virginia Polytechnic Institute and State University
}

\begin{abstract}
This ethnographic study examines the role of ideology in the development of organizational dilemmas in the Clamshell Alliance, an anti-nuclear protest group active in New England during the late 1970s. In 1977, the Alliance received national recognition for its use of consensus decision making and nonviolent civil disobedience during a highly publicized two-week incarceration following an attempted occupation of the Seabrook nuclear plant. But over the next few years, sharp internal disagreements developed over the use of these strategies, leading ultimately to a factional split. I extend theory from symbolic anthropology to integrate the analysis of ideology into the study of resource mobilization without sacrificing the latter's emphasis on rational calculation. My analysis shows that the Alliance's anti-nuclear ideology established an egalitarian identity for the group which structured both the initial selection of strategies and later efforts to modify them.
\end{abstract}

In April 1977, 1,414 members of the Clamshell Alliance were arrested and jailed in National Guard armories for trespassing on the site of a nuclear power plant in Seabrook, New Hampshire. They were attempting to stop construction of the plant through an act of civil disobedience, a nonviolent "occupation" of the site. Certain that their actions were legitimate, Alliance members collectively refused bail and continued their protest in the armories, capturing national attention in the process. The group exhibited an extraordinary sense of solidarity, making decisions according to a radically egalitarian consensus process. After two weeks of sustained negotiations, a frustrated Governor finally relented and granted favorable conditions for their immediate release.

Participants in the protest viewed this event as a major success in their effort to stop nuclear power through the new method of "direct action." Others around the country apparently agreed, for the event sparked the rapid development of three dozen similar groups during the next twelve months. Abalone, Breadbasket, Catfish, Conchshell, Dogwood, Palmetto, SHAD, and other such alliances hailed nonviolent direct action as the perfect alternative to the "indirect" legal strategy used by earlier anti-nuclear groups. According to the new view, the indirect legal strategy had failed to stop even one nuclear plant because it involved working within the existing atomic-industrial structure rather than attempting to change it.

During the next few years, direct action alliances flourished within the anti-nuclear movement; they grew in size and number, mounted frequent protest actions, and gained national recognition. By 1979, the term "anti-nuclear" had become virtually synonymous with the direct action style of opposition. Yet while they developed a growing public presence, the alliances also suffered severe internal conflicts over the appropriate organization of group strategies and tactics, conflicts which centered on the use of consensus decision making and civil disobedience. Disagreement frequently led to disaffection, and the alliances declined in membership and activity. The Clamshell Alliance itself split into two groups in 1979, both of which disbanded by the end of 1981 .

This article examines the role of ideology in the development of the organizational

* The fieldwork for this article was supported by NSF Grant \# BNS-7910334 and by a Faculty Research Grant from Michigan Technological University, Houghton, Michigan. I also acknowledge the continuing support of Virginia Tech's Center for the Study of Science in Society. I thank the anonymous reviewers of this journal for their helpful comments. Correspondence to: Center for the Study of Science in Society, Virginia Polytechnic Institute and State University, Blacksburg, VA 24061. 
dilemmas within the Clamshell Alliance. The analysis is based upon ethnographic evidence collected from the Clamshell Alliance during 1978-79 through participant observation, interviews, and Alliance publications and other documents, as well as on further interviews and documents collected in 1982. ${ }^{1}$ In an earlier study drawing upon resource mobilization theories of collective action, Barkan (1979) explicitly deemphasized the significance of ideology in explaining the development of strategic, tactical, and organizational dilemmas in the anti-nuclear protest movement. Instead, he viewed these dilemmas as the casual product of the group's resource attributes, especially its low potential for societal disruption. More recent studies of resource mobilization in other social movements have placed greater emphasis upon ideology, but these have encountered a conceptual barrier in identifying the theoretical role of ideological beliefs. In this study, I argue that the anti-nuclear ideology of the Clamshell Alliance defined a radically egalitarian identity for the organization, structuring its selection of consensus decision making and nonviolent civil disobedience as strategies for realizing that identity. Also, when the Alliance encountered obstacles that undercut the legitimacy of those strategies by giving them contradictory meanings, its ideological identity sharply limited the search for acceptable alternatives. The theoretical approach used to make this argument avoids difficulties associated with previous conceptions of ideology as a psychological resource to be manipulated and maximized by drawing upon a structural conception of ideology from symbolic anthropology. As seen from this point of view, the Clamshell Alliance ideology provided an interpretive framework that effectively defined organizational strategies and established criteria for assessing their legitimacy.

I begin my analysis by summarizing the problem of ideology in resource mobilization theory and outlining my alternative approach. I then provide an ethnographic account of the Clamshell Alliance's experience with consensus decision making and nonviolent civil disobedience, reviewing both its early successes and later failures. After briefly describing the internal structure of the Alliance's anti-nuclear ideology and its egalitarian identity, I then argue that the disagreements within the Alliance were centered on alternative proposals to realize its core identity. I conclude by drawing some implications of my theoretical approach for the analysis of organizational strategy and identity in social movements.

\section{IDEOLOGY AND SOCIAL MOVEMENTS}

Recent sociological interest in the structural role of ideology in social movement action is in fact a reemergence of this issue under a new set of theoretical conditions. Smelser's (1963) value-added model linked collective behavior theory to structural-functionalism and defined a central structural role for ideology which he construed as irrational "generalized beliefs."2 Later theories rejected the assumption that beliefs in social movements

1. During 1977-79, I conducted fieldwork among three different direct action anti-nuclear groups, including the Clamshell Alliance of New England, the SHAD Alliance of New York, and the Bailly Alliance of northern Indiana. I attended biweekly meetings, Congresses, and protest actions of the SHAD and Bailly Alliances for periods of eleven and nine months, respectively, and I traveled to New England on five occasions to attend Congresses, regional meetings, and a protest action of the Clamshell Alliance. In 1982, I conducted follow-up interviews with eleven former members of the Clamshell and SHAD Alliances. I also located the files of the Clamshell Alliance rapidly deteriorating in a damp Massachusetts barn, and xeroxed over 300 pages of detailed meeting minutes, individual proposals, and other publications that I did not already possess. The Clamshell Alliance documents cited in this paper are available in my files, along with other cited unpublished materials. Most are not dated, but I am confident that I have correctly estimated the year each was completed.

2. Although Theory of Collective Behavior did not explicitly equate generalized beliefs with ideology, evidence of a close correspondence appears in several places. A reference to ideology in the index directs the reader to 
were necessarily irrational. Relative deprivation theory left open the question of rationality by deemphasizing all structural phenomena, including ideology, and instead focusing on wholly psychological mechanisms. Resource mobilization theory took an opposite approach, and replaced irrational beliefs with their utilitarian opposite the maximization of self-interest. This analytic model of resource mobilization reemphasized structural mechanisms but rejected ideology completely from consideration by relegating it to the realm of psychology. Ideology was shelved with other "mental phenomena" (Walsh and Warland, 1983:765) as either a structurally-given constant or a product of mobilization processes. Consequently, the supply of resources available to social movement organizations became the key variable in determining action (Jenkins and Perrow, 1977; McCarthy and Zald, 1973, 1977; Oberschall 1973).

In recent years, proponents of resource mobilization theory have expressed uneasiness with its "economistic slant" (Zald, 1980:60) and the corresponding lack of attention given to the contents of grievances (Gamson et al., 1982; Jenkins, 1983; Oberschall, 1978). Also, empirical applications of the theory in studies of the women's movement (Carden, 1978), farm worker's movement (Walsh, 1978), anti-busing movement (Useem, 1980), and anti-nuclear movement (Walsh, 1981; Walsh and Warland, 1983) have found ideology to be a key variable in mobilization processes. Considerable interest has developed in reintegrating ideology into resource mobilization theory, but it has proven difficult to provide a role for ideological beliefs as a variable in a model that emphasizes rational responses to structurally-given opportunities. For example, Useem (1980:368) advocated an "integrated theory" bringing together the older and newer theories, while Walsh and Warland (1983:779) suggested an "additive model"; but neither offered a fully-developed theoretical alternative. Likewise, Jenkins (1983:54) recommended focusing on the role of "collective identities" and Zald (1980:70) recommended that macrostructural analysis be linked to study of the "internal socio-psycho logic" of "meaning systems," but neither elaborated a framework for fulfilling these tasks.

A potentially fruitful avenue for integrating the analysis of ideology into social movement theory without sacrificing the current emphasis on rational calculation is suggested by a symbolic anthropological conception of ideology as a component property of social action. Viewed as a cultural meaning system implicit in social action, ideology can be identified through the systematic observation of everyday public behavior. The defining characteristic of a specific ideological system lies in the meanings that it attributes to certain key relationships in society. Although any ideology can be shown to distort the social reality it represents by offering a simplified model, every ideology asserts nonetheless that the meanings it gives to these key social relationships are accurate descriptions. Thus, Geertz (1973:216), in founding this approach to the concept, characterizes ideologies descriptively and nonpejoratively as "schematic images of social order."

An important implication of a symbolic anthropological approach is that ideologies are not viewed as epistemologically distinct from institutionalized systems of cultural meaning, such as religious, political, ritual, and class systems. The source of this standpoint is the theory that the analysis of cultures can be modeled on the analysis of lan-

pages 8-81, which spans the entire introduction to the concept of generalized beliefs. At one point in the text, Smelser appears to classify ideologies along with rumors and superstitions as types of generalized beliefs (1963:80-81), and at two points he shifts without explanation from a discussion of generalized beliefs to a description of ideologies $(1963: 99,113)$. In addition, in a more recent textbook on social theory, Smelser substitutes ideology for generalized beliefs: "[I]deology serves as a bridge between discontent and action. It gives meaning to the social problem; it identifies it and, perhaps, those responsible for it. Ideology defines a problem in terms of right and wrong and offers a guide for actions to redress the wrong" (1984:352). 
guages, i.e., as communicative systems (e.g., Levi-Strauss, 1966, 1969). For just as linguists describe speech as presupposing shared grammatical structures, so all social action could be described as communicative action that presupposes shared structures of cultural meaning. "Cultural analysis" thus developed as the process of identifying categories of meaning implicit in instances of verbal and nonverbal behavior. Its product is a "cultural account" of social action, which describes observed behavior in terms of the categories of meaning that it implements (Sahlins, 1976; Schneider, 1969). The methodological criterion for testing a cultural account is its plausibility rather than its causal efficacy. This criterion is usually satisfied by demonstrating that the same categorical distinctions are communicated by different actors in a range of actions taken from different contexts.

Ideologies perform a distinctive symbolic function in this analytic framework by communicating actor identities, or culture-specific understandings of self in contradistinction to outsiders. For example, Galaty (1982:3) suggests that an ideology "provides a mode by which a stable and coherent image of the . . . cultural . . . self can be publicly presented, thus establishing continuity of identity through perpetual reproduction of that image." In other words, social action that implicitly conveys an ideology also communicates a public identity.

Cultural accounts of ideologies generally focus on their internal structures and the complex identities they establish. Cultural analysts illustrate these relationships with sample descriptions of "typical" actions. However, studies of social movements have focused mainly on religious ideologies (Dolgin, 1974; Fernandez, 1978; Nicholas, 1973; Whitehead, 1974), while ideologies in other types of movements have escaped scrutiny. Yet, the cultural analysis of ideological identities can contribute to the study of resource mobilization in a variety of social movements by showing that the identities of organizations help to define the resources they manipulate and the actual strategies they employ. Social movement organizations rarely, if ever, manipulate all the resources or adopt all the strategies that are available to them. Such organizations often reject certain categories of resources and strategies as illegitimate. An organization's ideological identity provides a framework of meaning for identifying and evaluating the legitimacy of different categories of resources and strategies. That is, the identity serves as an interpretive lens distinguishing those resources and strategies that promise to fulfill the identity from those that appear to be inconsistent with it. From this point of view, processes of resource mobilization include selective processes of resource definition and legitimation. The study of ideology can provide access to those definition and legitimation processes. As we shall see below, the Clamshell Alliance provides a particularly clear case of ideological screening, for its identity as a participatory democracy drastically restricted the range of legitimate action.

\section{EARLY DEVELOPMENT}

The direct action opposition to nuclear power began in New England in 1974 when a group of veterans from the anti-war movement, who had been living "an alternative rural lifestyle free from both the . . capitalist society and . . . the hierarchical excesses and male chauvinistic failures of the New Left" (Mitchell, 1981:82), used the novel techniques of rallies, picketing, vigils, and nonviolent civil disobedience to oppose the construction of a nuclear power plant in Montague, Massachusetts. They achieved an early success when one member toppled a weather tower at the site, turned himself into authorities, and then was acquitted on a technicality after managing to turn his trial into a 
debate over the merits of nuclear power. "Positive action is the only option left open to us," he wrote in a statement handed to police, for "we must seize back control of our own community" (quoted in Wasserman, 1979:29). When construction at the Montague plant was postponed indefinitely in 1976, the attention of group members shifted to the recently approved Seabrook plant in southeast New Hampshire, and, together with several other groups interested in direct action, they formed the Clamshell Alliance in July 1976.

The new Alliance immediately began to plan nonviolent "occupation/restoration" actions at the site. The strategy was inspired by an earlier occupation in Wyhl, West Germany, where 28,000 protesters had forced their way onto a nuclear plant site in 1975 and then occupied it for more than a year, leading to the plant's cancellation (Gyorgy et al., 1979). The Clamshell's first two occupations were held three weeks apart in August 1976. Eighteen members were arrested at the first and 180 at the second, while groups of several hundred people held support rallies outside the gates.

The third occupation attempt on April 30, 1977 convinced Alliance members that the Whyl model could have a major impact in this country. Their two-week incarceration not only disrupted the law enforcement operations of the state temporarily, but also showed that the Alliance could act as a unified force for social change. Potential occupiers attended a mandatory five-to-seven hour training session on nonviolent direct action, which produced what was widely characterized as "incredible Clamshell solidarity" (Wolfe, 1977:9; Clamshell Alliance [CA], 1978c). One occupier reported that despite the almost continuous strategy meetings, "decision making continued to work by consensus," and "amazingly, we consistently reached complete agreement" (Horowitz, 1977:3). Another later observed: "There is a sense that it was a mystical event; something greater than a well planned and executed direct action project" (Rosenblith, 1977:4). A third asserted that "the Seabrook occupation communicated two messages": "No Nukes" and "Nonviolence Works" (Farren, 1977:1). By most accounts, all that was needed was a still larger force (Hilgartner, 1977:7).

The planning of a fourth occupation for June 1978 employed a newly-expanded consensus mechanism that included an iterative process of local, regional, and Alliance-wide decisions. "Spokespersons" from 13 regions conveyed local decisions on lesser issues to monthly Coordinating Committee (CC) meetings, while major issues were debated at Congresses held every few months (CA, 1979c). By May 1978, more than 5,000 occupiers had completed training when the state, seeking to avoid mass arrests, offered the Seabrook site for a legal, three-day rally (CA, 1978b). The offer came too late for the Alliance to reach consensus as a whole, so the Coordinating Committee, persuaded that a refusal would evaporate their rapidly diminishing support among frightened local landowners, accepted it. Over 20,000 people attended the legal rally, but the explicit violation of the consensus process, along with the action's failure to make visible progress in stopping the plant and restoring the site, produced much frustration and anger. One participant reported frequent "charges of 'elitism' and 'subversion of the process,', as well as "strong hints at police agentry and outright personal attack" (Wasserman, 1979:113).

Acceptance of the legal rally forced into the open sharp disagreements over whether or not consensus decision making and civil disobedience were appropriate means for stopping the Seabrook plant (CA, 1979b; Jezer, 1978). Reliance upon consensus had prevented decisive Alliance action, and future decision-making needs were highly uncertain. Civil disobedience produced arrests rather than restoration, and its effectiveness de- 
pended upon the participation of outside groups, such as landowners who controlled access to the site and the news media which publicized the event. A collection of members that became known as the "action faction" favored an occupation that, while nonviolent, would eschew civil disobedience and resist forcible removal from the site. Unable to agree upon specific plans, the Alliance sought to maintain public visibility by sponsoring a series of "wave actions" by smaller groups (Tracey, 1978). These culminated with a failed attempt at blockading a reactor pressure vessel as it was being transported to the site early in 1979 (Ormes, 1979).

In January 1979, decision making stalled at an Alliance Congress when none of the 55 proposals passed and discussion degenerated into angry debate. Participants reported "irreconcilable political and personal differences," "disagreements based on strong principles that people do not want to compromise," and a sense of "distrust," "frustration," and even "hatred" (CA, 1979b). Some proposed to dissolve the Alliance, while others pleaded for more discussion and attempts at resolution. Finally, they reached a decision to hold a new Congress that would focus entirely on "soul-searching" and "reconciliatory healing" (CA, 1979b).

\section{CREATIVE CONSENSUS}

The Congress was held on a weekend in March 1979 in Worcester, Massachusetts and was attended by more than 150 members, including the author. It began early Friday evening with men's and women's discussion groups to elicit views about the major strengths and weaknesses of the Alliance. These meetings were segregated by sex to allow free discussion of the problem of male dominance. The agenda for the next two days consisted of alternating small-group and plenary sessions to clarify problems and define solutions, culminating in a decision-making session on Sunday afternoon (CA, 1979a).

Consensus decision making and civil disobedience quickly emerged as the central issues. The initial discussions and the first plenary session on Saturday morning were both marked by impassioned purges of long-standing differences. Those who emphasized the Alliance's strengths focused on the "sense of community" produced by the consensus process and the advances made by civil disobedience in educating the uncommitted public, gaining local support, and building a mass movement. Those who emphasized its weaknesses viewed consensus as inhibiting efficient group action and civil disobedience as a weak gesture incapable of stopping nuclear power.

Randomly-selected discussion groups met early Saturday afternoon to isolate and rank specific problems according to their importance, (or as the facilitator said, "people who feel uncomfortable with this can join any of the random groups or form other groups"). Their suggestions were combined to produce four categories of issues to be considered by problem-solving workgroups:

(1) Structure and Process - consensus decision making, membership, power relationships, decentralization, finances;

(2) Future Actions - Seabrook blockade, Seabrook occupation, Wall Street;

(3) Growth of the Alliance - clarify goals, labor and business outreach, alternative energy, specifying political perspective;

(4) Definition of terms - civil disobedience, direct action, nonviolence, property destruction, membership.

Structure and process had been on the top of every list, for most everyone had agreed 
with the man who said, "I don't see how we can consider future actions until we resolve our problems with structure and process. Structure and process affect everything."

Over half of the participants joined the structure and process group, and another third formed the future action group. While the action group met as a single body, the stracture and process group divided into six smaller groups, which came together and separated three times during Saturday evening in an increasingly pressured attempt to construct a proposal for modifying the consensus process. No one speculated publicly about the consequences if no clear proposal emerged, but the obvious sense of urgency conveyed their collective anxiety.

Many people had come to the Congress already committed to shifting from consensus to an 80 percent majority rule in hopelessly deadlocked situations, a model called "creative consensus." However, openly campaigning for the model would not have been "proper process," so members of the workshop systematically considered all possible alternatives to consensus. After agonizing over the problem until after midnight, they received formal comments from regional groups on Sunday morning, and then finalized a single proposal by mid-afternoon. The creative consensus proposal emerged virtually intact, although it included six additional provisions to insulate majority rule from possible abuse.

Although the entire group was exhausted, the relentless push for an Alliance decision continued as the final session began two hours late. A female facilitator slowly described the proposal, along with each previously expressed reservation, and then happily reported that the workgroup had approved it by consensus. A new discussion ensued that once again scrutinized every conceivable implication:

What about at actions? How do we make decisions there? . . .

This doesn't address the real problem we have in the C.C. of whether one person in one group can block or whether everyone in one group has to block. . .

I think we should go to 90 percent instead of 80 percent. An 80 percent vote in this group could mean that 30 people could be overruled, which I find shocking. . . .

Yes, that's right, I didn't realize that. . . .

There are many people not here who would be here if they knew we would go to majority rule. . .

Yes, but there are also a lot who would be here if we didn't operate on consensus. . . .

By making it effective immediately, are we creating a situation where we usurp the power of those people not present? ...

Hey, this is an Alliance-wide Congress. We can't get hung up on what people who don't show up think. . .

I think we should add to the proposal a provision that no more than 40 percent of those present abstain so that we don't end up with minority rule. . .

How about 85 percent instead of 90 ? . .

Is there any way we could apply this new process to the C.C.? . .

You know, this is not really a new process, but a safety valve on the old process. It is not simple majority rule. It is consensus-seeking majority rule, which is different. . . .

I like the idea of a trial period. It softens the blow of the change and leaves open the possibility of shifting back if we feel the system is being abused. . . .

I think consensus is what our movement's all about, and I'm not sure we should ever move from it.

Look, the Palmetto Alliance has already been through this. They had all the problems that we have with consensus so they finally passed this majority-rule proposal. I just got a letter from a person in that group and he says that they've never had to use it. Okay? 
I'm the vibes watcher. So far 23 men and only 7 women have spoken. Now I don't think that men are that much dumber than women that they have to ask that many more questions. Now c'mon.

I too prefer 85 percent to 90 percent. Ninety percent seems awfully high to me and I know a lot of other people around here agree with me. . .

Just a minute. I too think we can get by with 85 percent or even 80 or 75 . However, I think we should recognize that there are many people here who are understandably fearful of any shift away from consensus and would like the highest percentage possible. Recognizing that fear, I think we should demonstrate our solidarity by accommodating ourselves to the 90 percent figure.

This continued for over two hours, exceeding the 90-minute time limit allotted for discussion.

Finally, the facilitator rose to ask for specific, formal objections. Five hands went up, accompanied by groans of frustration. Patiently inquiring into each concern, she asked if the individual were willing to have it noted for future reference without blocking the decision. One by one, each agreed. A wave of recognition suddenly rushed through the group as the facilitator asked, "Do we have consensus on this proposal?" For an uneasy moment, no one answered, as consensus exists only when no one objects. But then one man shouted "Yes!," others echoed him, and the entire group leaped to its feet in a spontaneous cheer. Amid cries of "It works! It works!," men and women ran around hugging and congratulating one another. Those few who stood quietly basked in the general sense of relief.

The long weekend had appeared to be worth the work. Deciding to accept an emergency shift to a 90 percent majority rule had saved the Alliance, and future plans could once again be discussed.

\section{ORGANIZATIONAL SPLIT}

The jubilation over successful resolution of the consensus decision-making issue masked the disaffection of the action faction. The Congress left the issue of civil disobedience unresolved and turned the future action workgroup into the Direct Action Task Force (Hard Rain, 1979). At the following Congress in June, the Task Force presented a proposal for an occupation attempt that would include cutting fences around the plant to facilitate entry, and wearing protective clothing such as helmets and gas masks. ${ }^{3}$ Others argued vigorously that cutting fences was violent, and that protective clothing would incite police violence. The disagreement produced a new stalemate, for a sufficient majority did not exist to settle the issue, and this time a formal dissolution was averted only by an informal split. The Alliance agreed to endorse the occupation if the Task Force sponsored it as a separate organization.

The Coalition for Direct Action at Seabrook formed shortly thereafter with decision making based on a 75 percent majority rule. It organized two-day occupation attempts in October 1979 and May 1980, both of which failed miserably. At the first, 400 policemen with badges removed used water cannons, tear gas, and, in some instances, clubs to prevent 3,000 occupiers from entering the site, but made no arrests. The liberal use of police force shocked many first-time participants into advocating a return to civil disobedience, while others disagreed. Several months of discussion produced a new strategy that became "all things to all people" and involved occupying the site by sitting down and blockading the gates. ${ }^{4}$ However, a force of 900 policemen easily repelled a contin-

3. Confidential interviews: Boston, Massachusetts, August 10, 1982; and Portsmouth, New Hampshire, August 13, 1982.

4. Confidential interview, Boston, Massachusetts, August 11, 1982. 
gent of 1,800 people. Coalition meetings continued through 1981, and an unsuccessful attempt was made to blockade the transportation of a second reactor pressure vessel to the site. But meeting attendance declined, the group's office closed, and by early 1982 the meetings simply ceased.

Meanwhile, the Clamshell Alliance attempted to continue on its own, despite a rapid decline in participation. It sponsored a June 1979 rally called "Turning Tide" in order to show that "the nukes are on the run" (CA, 1979d), but the disappointing attendance of several hundred people left the organization deeply in debt to its remaining active members. The Alliance did participate formally in a civil disobedience action on Wall Street on October 29, 1979 - the fiftieth anniversary of the stock market crash - in order to focus attention on nuclear economics; but the action was organized by the SHAD Alliance of New York (Manhattan Project, 1979). Alliance meetings continued until early 1981, when a site was selected for a new Congress even though no one from that region was present, and the meeting was never held.

\section{THE CLAMSHELL IDENTITY}

In a comprehensive review of the Clamshell Alliance's problems as these appeared in 1978, Barkan (1979) argued that the growing disagreements were the product of a need to maximize two different sets of resources simultaneously - public support and group solidarity. According to this argument, a group's need for public support is a function of both the level of its internal resources and the degree of threat it poses for societal disruption, and group solidarity is a universal need of social movement organizations. The organizational problems of the Clamshell Alliance, then, could be traced to its low threat of disruption, for "although anti-nuclear activists possess many internal resources and skills . . . their numbers have not been large enough for their protest actions to present a great threat of disruption to atomic plants" (Barkan, 1979:22-23). Thus the organization adopted strategies to build public support at the expense of internal solidarity, which in turn produced the escalating conflict.

But was the low threat of disruption by the Clamshell a cause of its organizational strategies or, alternatively, was it a product of these strategies? The structural attributes of the group vested it with a high level of internal resources that made a wide range of strategies and tactics theoretically possible. For example, if 20,000 people had gathered at Seabrook to demonstrate their willingness to use bombs and other violent tactics, the Clamshell Alliance conceivably could have threatened to disrupt not only nuclear power plants but also the economic stability of the United States. But the Alliance explicitly chose nonviolent direct action and rejected other available tactics as illegitimate. This self-limiting constraint on resource utilization can be understood only by examining the organization's ideological identity.

The ideological model communicated by Alliance actions portrayed U.S. society as a power hierarchy where a monolithic union of industry and government forced the monstrous dangers and costs of nuclear power upon ordinary citizens without their consent. This "atomic-industrial establishment" dominated the citizenry by depriving individuals of control over their lives, hiding truths about the technology and seeking only to advance its own economic and political interests. The establishment used the technology of nuclear power as its primary instrument of domination.

The Alliance's "Founding Statement" (CA, 1976), for example, implicitly conveyed this view of nuclear power and the establishment while asserting that "nuclear power poses a mortal threat to people and the environment"; that "people should not be ex- 
ploited for private profit"; and that "energy needs can be adequately met through utilization of non-nuclear sources." The 600-word "Declaration of Nuclear Resistance" (CA, 1977a) communicated the same model by characterizing the nuclear industry as seeking "to concentrate profits and the control of energy resources in the hands of a powerful few, undermining basic principles of human liberty." Building a plant at Seabrook "could lock our region into a suicidal path," for the technology was "dangerous to all living creatures and their natural environment," an "assault on life itself." Nuclear plants were "an economic catastrophe," requiring "immense investments of capital" and creating "fewer jobs than comparable investments in conservation and solar energy." And the "centralized nature" of nuclear power "[took] control of energy from local communities and strengthen[ed] the monopoly of the utilities." Similarly, an official history of the plant (CA, 1978a:4-5) described the utility company as coming to "rape the land" and force local people to "sacrifice their homes to the nuclear monster," all with the support of the government, which had "yawned and rubber stamped the project," "siding with the privately-owned electric power monopoly from the beginning."

The most important category of communicative acts which indicated that nuclear power was an instrument of domination consisted of technical claims about its hazards and costs. ${ }^{5}$ The Alliance invested considerable effort in trying to show that the magnitudes of the hazards and costs associated with nuclear power were so great as to be unconscionable. For example, shortly after the Alliance formed, study committees spent months researching the problems of nuclear accidents, core meltdowns, low-level radiation, terrorism and sabotage, transportation, waste disposal, and nuclear economics. Then they published numerous pamphlets and articles detailing virtually every reported worst-case scenario (e.g., CA, 1977b,c,d,e,f; see also 1976-1979 issues of the bimonthly Clamshell Alliance News). In addition, two books by Alliance members emphasized technical critiques of nuclear power (Gyorgy et al., 1979; Wasserman, 1979), and virtually every new local group began by learning the "basic facts and figures of nuclear power" in order to better communicate its position to outsiders (CA, 1978a:2). Finally, since the technology could not dominate without a dominating agent in control, each technical critique also reported all available evidence that the nuclear industry and its supporters were more than willing to distort and cover up the facts in order to preserve hegemony over the citizenry through nuclear power.

The Clamshell ideology located the Alliance in this societal structure and defined its organizational identity in opposition to the atomic-industrial establishment. Since the Alliance was both the opponent and the opposite of the establishment, the Clamshell identity had two components. As its opponent, the Alliance was an instrumental actor, actively working to stop nuclear power and overcome domination. As its opposite, the Alliance was an egalitarian organization, a collectivity of equal citizens seeking to avoid propagating domination through its own actions. The Alliance thus fought domination on both the outside and the inside.

Alliance actions routinely communicated both components of this identity. For example, the Founding Statement (CA, 1976), described the Alliance as working to "reassert the right of citizens to be fully informed and then to decide the nature and destiny of their own communities" by seeking to "stop all construction of a nuclear power plant in

5. Technical claims were most important because in Western culture science is the source of epistemological authority. Claims valid in scientific terms were most likely to carry the unchallengeable status of "fact" and thereby provide convincing support for an ideological model consistent with them. See Downey (1986) for further elaboration. 
Seabrook, New Hampshire." Its methods would be limited to "direct, nonviolent action, such as one-to-one dialogue, public prayer and fasting, public demonstration, site occupation, and other means which put life before property" (CA, 1976). The Declaration of Nuclear Resistance (CA, 1977a) aligned the group as "unalterably opposed to the construction of this and any other nuclear plant," because stopping nuclear power would make it possible for the "power supply [to] be decentralized, so that enviromental damage is further minimized, and so that control can revert to the local community." Similarly, an early desision (CA, 1979c:2) identified Alliance goals as to "permanently halt nuclear power," to "promote clean, safe, low-cost, and efficient alternate energy sources," to "promote democratic, public control over energy," and to "promote a pollution-free society in which the means and resources for satisfying basic human needs are controlled cooperatively by local communities."

Note that while the Clamshell identity was politically radical, it was not revolutionary in the usual sense. Social change would come not by replacing one powerful group with another, but through public acclamation. Also note that the identity was not anti-technology, as is sometimes claimed, for society was to be reorganized by developing solar and other decentralized energy technologies. Nuclear power was condemned, not because it was an advanced technology, but because it was an advanced technology that produced a structure of social domination.

\section{THE DILEMMA OF CONSENSUS DECISION MAKING}

The Clamshell identity structured the Alliance's selection of organizational structure and protest strategies. The group initially adopted the consensus mechanism in order to realize its identity through intraorganizational relationships. "The success of the process," reported one former member, "was sort of a goal." 6 Its highly publicized success in the armories following the 1977 occupation attempt displayed its instrumental value at an early point. But the greatest significance of consensus decision making lay in its egalitarianism. Unlike majority rule, consensus guaranteed "the fundamental right of . . . all persons to be able to express themselves in their own words and of their own will," and insured "the fundamental responsibility ... to assure others of their right to speak and be heard" (CA, 1978d).

Meetings organized under consensus were strictly horizontal in structure, with no official roles possessing differential authority. The central figure was the facilitator, who, in contrast with a chairperson, was supposed to lead without becoming a leader. Said one training packet: "A good facilitator helps participants be aware that they are in charge, that it is their business that is being conducted, and that each person has contributions to make to the group" (CA, 1978b:12). Every meeting included a "vibes-watcher," who paid attention to the "emotional climate," observed the relative participation of men and women, and proposed changes as needed (CA, 1979b:16). Accurate minutes by the "note-taker" were valued not only to maximize efficiency but also because misrepresentation constituted an insidious form of coercion (CA, 1979e). Finally, in conveying the decisions of regional groups to the monthly Coordinating Committee meetings, "spokespersons" carried no representative authority (CA, 1979c).

Formal deliberation was not simply an exchange of ideas but a highly-disciplined effort to allow the common ground of an egalitarian collectivity to emerge: "consensus allows us to recognize our areas of agreement and act together without coercing one another"

6. Confidential interview, Boston, Massachusetts, August 10, 1982. 
(CA, 1978d:1). A consensus decision therefore constituted a collective achievement because, more than a 100 percent majority, it was the product of the group's unencumbered gravitation toward "collective truth" (CA, 1979e:8). Although conflict was not to be avoided, the emphasis was on accommodation, as explained by a Clamshell member at a training workshop: "Under majority rule, when you and I disagree I try to convince you that I am right and you are wrong; under the consensus process, I try to accommodate myself to your objection."7

Since each Alliance decision required consensus at local, regional, and Alliance-wide levels, any single individual could have blocked the action of the entire organization. Although dreaded for its ability to prevent group action, blocking was legitimate if based upon "serious, principled objections," because it meant that no area of common agreement had yet been found and that any group decision would therefore be illegitimate (CA, 1978d:3). However, lesser disagreements could be resolved without blocking through the alternative devices of "non-support," "reservations," "standing aside," and "withdrawing from the group" (CA, 1978d:13).

Unfortunately for the Alliance, the early instrumental success of the process was shortlived. One reason was that reaching consensus consumed too much time. Week-night meetings of local groups averaged three to four hours of sustained discussion, often producing what was called "consensus by attrition," which worked, as they said, only for those who stayed long enough. Congresses always required two to three days to reach but a handful of decisions, with many members participating only in the final sessions. The CC system required a minimum of two months to reach an Alliance-wide decision, since each new proposal had to go back to local groups for deliberation. Many found Clamshell meetings to be a "disaster," and some felt that the process had driven away numerous potential members. ${ }^{8}$ A second reason was that the increasing size of the organization made a consensus more elusive, for the area of common agreement became smaller as the group grew larger. The larger size also increased the potential that a single disruptive individual or agent provocateur would immobilize the entire group by simply expressing disagreement, which happened, in fact, on several occasions (Hilgartner, 1979).

Because of these difficulties, continued use of consensus produced a tension between the instrumental and egalitarian components of the Clamshell identity, reinforcing the latter at the expense of the former. But when the Coordinating Committee accepted the state's offer of a legal rally in 1979 for instrumental reasons, it committed the opposite error by assuming illegitimate authority. This action severed the egalitarian bonds that constituted the core of the organization's identity and precipitated a decision-making crisis. The dispute that followed over whether or not to modify the consensus decisionmaking rule was a disagreement over whether to deal with the growing ideological contradiction within the Clamshell Alliance by placing disproportionate emphasis on the egalitarian component and asking everyone to try harder to reach consensus, or by emphasizing the instrumental component and making decisions by majority rule. Formal dissolution was an unsavory third alternative because it would have signified a collective acceptance of domination by the establishment. When the Congress finally agreed on the apparently minor shift to 90 percent majority rule in March 1979, the result was both exultation and relief because, by seemingly restoring the Alliance's instrumental capabili-

7. Valparaiso, Indiana, January, 1978.

8. Confidential interviews, Boston, Massachusetts, August 10 and 11, 1982. 
ties with a minimal loss in egalitarianism, the consensus decision and the new structure had reaffirmed the Clamshell identity to a maximum extent, if only temporarily.

\section{THE DILEMMA OF CIVIL DISOBEDIENCE}

The use of nonviolent direct action against nuclear power communicated the Clamshell identity through external relationships. Nonviolence was consistent with the egalitarian component of the Alliance's identity since it fought establishment domination without propagating it. "Nuclear power is a violent technology," asserted one occupation/restoration handbook (CA, 1978a:14); "by opposing it nonviolently, we make it clear that the real nuclear terrorists are the people and institutions who perpetrate that technology, not those who work to stop it." Combining nonviolence with direct action emphasized the instrumental component and distinguished the Alliance from the earlier nuclear opposition that had failed to stop nuclear power through indirect means. For example, one early pamphlet (CA, 1977g:2) asserted that "direct action is needed" because legal opponents had faced "a stacked regulatory deck." A group of members (CA, 1979c:6) found the strength of direct action to lie in "acting for ourselves without appealing to or recognizing the legitimacy of the state or corporate authority." And the trainer at a workshop on direct action explained that "direct action evolved out of the personal and collective desire to act for ourselves without the mediation and resulting distortion contributed by representatives, the media, bureaucrats, "heavies,' or leaders."

Although direct action included "public rallies, leafletting, canvassing," "using the media to publicize the dangers of nuclear power," and "boycotts, strikes, and withholding rate payments used to build nuclear power plants," the most important tactic, by far, was civil disobedience (CA, 1978a:14). The objective of civil disobedience, where "laws are broken to prevent an injustice," was to undermine the popular support that legitimized the establishment and its technology by demonstrating a willingness to risk arrest, jail, and personal harm (CA, 1978e:1). In using it, the Alliance explicitly identified itself with Gandhi's method of "Satyagraha," which was understood as "a force born out of truth and love" (CA, 1978e:1). Coupling it with the strategy of occupation/restoration promised "fundamental change," as it did in West Germany where residents who had "led essentially normal lives governed by bureaucrats, private property and the marketplace took over a plant and made it their own: farming on it, meeting on it, and living on it." They had succeeded in "transforming reality from isolation, cops, money, fences, and obedience into a moving collective experience" (CA, 1979f:3).

The purpose of formal training was to replace patterns of dominance/submission with interpersonal bonds, enabling protesters to "deal with fears and feelings," to "remember what of you cannot be hurt and taken," and to "claim back your humanness, your ordinariness, transcending moments of abnormality and crisis" (CA, 1979b:5). Its highlight was the exercise of "role-playing," through which trainees prepared to make personal contact with their adversaries, "who are as threatened by nuclear power as we are," by acting out their roles (CA, 1978b:7). In the armories, for example, sustained contact with police and National Guardsmen produced "an extraordinary consciousness change on both sides" (American Friends Service Committee, 1977:1). The product of nonviolence training was the formation of "affinity groups," which were to be "based upon real personal 'affinities'” (CA, 1978c:1).

Parallel to the evolving problem with consensus, the early instrumental success of civil

9. Valparaiso, Indiana, January, 1978. 
disobedience did not last, due largely in this case to external action by the state. Continued reliance upon civil disobedience reinforced the developing contradiction between the instrumental and egalitarian components of the Clamshell identity. For many members, the state's successful conversion of the planned civil disobedience action in 1978 into a legal rally provided decisive evidence of the instrumental weaknesses of civil disobedience. The Coordinating Committee's position was that refusing to participate in the rally would have sent the message to the public that the Alliance was interested only in breaking the law, thereby undermining its egalitarian identity. And, since the original instrumental/egalitarian objective of civil disobedience was to snowball public support without propagating domination, accepting the offer appeared to be the only alternative that preserved it. But the rally produced no clear disruption of the construction process, and any increases in public support were, at best, hidden from view. Consequently, many Alliance members criticized both the event and civil disobedience as examples of "indirect" action, which depended upon a corporate enterprise, the news media, for their impact. In this view, civil disobedience had succeeded in 1977 only because authorities had made the twin mistakes of permitting occupiers access to the site and then setting high bail after the arrest, errors that would not be repeated.

The disagreement over whether or not to abandon civil disobedience once again involved a choice between dissolving the Alliance and placing disproportionate emphasis on one component of the Clamshell identity. The action faction implicitly emphasized instrumentalism with the proposal to occupy the site by tearing down fences and protecting themselves from tear gas. ${ }^{10}$ Others implicitly emphasized egalitarianism by pressing for strict "guidelines against property destruction and protective clothing" (CA, 1979b:9) and by arguing that a plant occupation was not successful if it did not produce a "grassroots movement" (Jezer, 1978). Agreement between the two was never reached, and the tension was never resolved.

Instead, the informal split between the Clamshell Alliance and the Coalition for Direct Action at Seabrook formally recognized the opposed preferences in new organizational identities. The Alliance sacrificed its identification with direct action, but then suffered the costs at its failed "Turning Tide" rally. The Coalition sacrificed egalitarianism, as a small group of people took control of planning and simply announced a change to 75 percent majority rule. ${ }^{11}$ But when its two occupation attempts failed, the Coalition was unwilling to assume a still different identity by rejecting nonviolence completely, and the organization was left without a strategy for continued protest.

\section{CONCLUSION: IDEOLOGICAL IDENTITY AND RESOURCE MOBILIZATION}

By viewing the anti-nuclear ideology of the Clamshell Alliance as a meaning system that established its public identity and thereby delimited categories of legitimate resources and strategies, we can see that ideology played a crucial role in the development of its organizational dilemmas during the late 1970s. The Alliance's identity as a radically egalitarian, yet instrumentally effective, organization structured both the initial selection of consensus decision making and nonviolent direct action, and the later disagreements over modifying them. Modifications became necessary because obstacles imposed internally by the limitations of time and group size and externally by the state introduced a tension in the Clamshell identity and undercut the legitimacy of the original

10. Confidential interviews: Boston, Massachusetts, August 11, 1982; and Portsmouth, New Hampshire, August 13, 1982.

11. Confidential interview, Boston, Massachusetts, August 10, 1982. 
strategies. But, not surprisingly, the tension proved to be irresolvable, even by a factional split. The group's anti-nuclear ideology drastically limited the pool of legitimate alternatives, and the experiment in large-scale participatory democracy came to an end.

The extreme nature of the Clamshell case provides a particularly clear picture of the role that ideology can play in constraining the set of resources and strategies available to a social movement organization. It also raises questions about the more general implications of this analytic approach for the study of social movements. I conclude by briefly describing three such implications.

First, as I suggested above, this approach provides a means for integrating the analysis of ideology into the study of resource mobilization, thus avoiding narrow utilitarianism without sacrificing the emphasis on rational calculation. But it does so at the cost of a change in the analytic program. Ideology appears not as a variable interacting with changing resources and strategies (cf. Freeman, 1979) but as one meaningful or symbolic precondition of their existence (alongside the structural attributes of the group). Thus, from this point of view, the changing resources and strategies of a particular organization must be analyzed in terms of their ideological meaning before their implications for possible changes in ideological meanings can be assessed. Ideologies do change, of course, but ideologies are seen in this framework as coming from other ideologies, and specific changes are never pure causal responses to changes in social circumstances. Thus, different kinds of method are required for examining historical changes in ideologies, resources, and strategies.

The second implication, a correlate of the first, is that ideology always plays a role in the process of resource mobilization undergone by voluntary social movement organizations. By establishing organizational identities and adjudging the legitimacy of means to realize them, ideologies always contribute to the definition of organizational resources and strategies. However, the uniqueness of the Clamshell case suggests that there may be significant variation in the extent to which ideological identities constrain the selection of resources and strategies and, therefore, in the extent to which the understanding of resource mobilization depends upon the analysis of identities. In cases where structural attributes sharply limit the pools of potential resources or where ideologies legitimate particularly large sets of alternatives, analysis of the constraining effects of organizational identities may prove less essential.

The third, and perhaps most provocative, implication of this approach is that it provides a theoretical basis for examining connections between the organizational trajectories of social movements and the substantive issues that the organizations raise. The even limited success that the Clamshell Alliance had in realizing its identity indicates that a substantial number of people found that identity, and the anti-nuclear ideology that established it, to be reasonable representations of contemporary society and the position of nuclear power within it. If it were not credible to view the technology as posing unacceptable hazards, then nuclear power could not be an instrument of establishment domination nor provide evidence of the existence of domination. Since social movement organizations frequently advance knowledge claims about the issues at hand, the Clamshell experience suggests that the epistemological status of such claims may be an important factor in resource mobilization processes, even to the extent that reasonableness may be a key criterion for success. In short, as Nicholas (1973) suggests, just as this approach begins to blur the distinction between ideology and objectivity, so it also may begin to blur that between social and epistemological processes in social movements. 


\section{REFERENCES}

American Friends Service Committee

1977 "PeaceWork: New England's Peace Movement Newsletter." Portsmouth, New Hampshire.

Barkan, Steven

1979 "Strategic, tactical, and organizational dilemmas of the protest movement against nuclear power." Social Problems 27:19-37.

Carden, Maren Lockwood

1978 "The proliferation of a social movement: ideology and individual incentives in the contemporary feminist movement." Research in Social Movements, Conflicts and Change 1:179-96.

Clamshell Alliance [CA]

1976- Clamshell Alliance News 1-4. Published bimonthly newsletter.

1979

1976 "Clamshell founding statement." Published leaflet.

1977a "Clamshell Alliance declaration of nuclear resistance." Published leaflet.

1977 b "It's a fact: understanding the Seabrook nuke." Published pamphlet.

1977c "Nuclear accidents: a look at the record." Published pamphlet.

1977d "Nuclear economics: an invitation to ruin." Published pamphlet.

1977e "New England and nuclear power." Published pamphlet.

$1977 \mathrm{f}$ "Union busting and the nuclear power industry." Published pamphlet.

$1977 \mathrm{~g}$ "What is the Clamshell Alliance?" Published pamphlet.

1978a "Seabrook '78: a handbook for the occupation/restoration beginning June 24." Published handbook.

1978b "First supplement to the occupation/restoration handbook." Published handbook.

1978c "Affinity group packet." Unpublished mimeograph.

1978d "Decision making and consensus." Published pamphlet.

1978e "Civil disobedience." Published pamphlet.

1979a "Welcome to the congress." Unpublished mimeograph.

$1979 \mathrm{~b}$ "Notes from the January congress." Unpublished mimeograph.

1979c "Decisions of the Clamshell Alliance." Unpublished mimeograph.

1979d "The turning tide rally." Published leaflet.

1979e "Proposals for consideration at the Clam Congress-March 1979." Unpublished mimeograph.

$1979 \mathrm{f}$ "The Clam journal." Published collection of articles.

Dolgin, Janet

1974 "Latter-Day sense and substance." Pp. 519-46 in Irving, I. Zaretsky, and Mark P. Leone (eds.), Religious Movements in Contemporary America. Princeton: Princeton University Press.

Downey, Gary L.

1986 "Risk in culture: the American conflict over nuclear power." Cultural Anthropology 1. ForthFarren, Pat coming November.

1977 "Seabrook occupation shows the power of nonviolence." PeaceWork 54:1.

Fernandez, James W.

1978 "African religious movements." Annual Review of Anthropology 6:195-234.

Freeman, Jo

1979 "Resource mobilization and strategy: a model for analyzing social movement organization actions." Pp. 167-89 in Mayer N. Zald and John D. McCarthy (eds.), The Dynamics of Social Galaty, John Movements. Cambridge, MA: Winthrop.

1982 "Being 'Massai'; being "People-of-Cattle': ethnic shifters in East Africa." American Ethnologist 9:1-20.

Gamson, William, Bruce Fireman, and Steven Rytina

1982 Encounters with Unjust Authority. Homewood, IL: Dorsey Press.

Geertz, Clifford

1973 "Ideology as a cultural system.” Pp. 192-233 in The Interpretation of Cultures. New York: Basic Books.

Gyorgy, Anna, and Friends

1979 "No Nukes: Everyone's Guide to Nuclear Power. Boston: South End Press.

Hard Rain

1979 "Direct action occupation: the orange proposal, Clams for Democracy statements." Unpublished mimeograph.

Hilgartner, Steven

1977 "The coming of age of the anti-nuke movement." PeaceWork 54:6-7.

1979 "Proposal to the CDAS." Unpublished mimeograph.

Horowitz, Shel

1977 "Peace, gentleness, community." PeaceWork 54:3. 
Jenkins, J. Craig

1983 "Resource mobilization theory and the study of social movements." Annual Review of Sociology 9:527-53.

Jenkins, J. Craig and Charles Perrow

1977 "Insurgency of the powerless: farm workers movements (1946-1972)." American Sociological Review 42:249-68.

Jezer, Marty

1978 "Who's on first? What's on Second? A grassroots political perspective on the anti-nuclear movement." WIN Magazine 14:4-17.

Levi-Strauss, Claude

1966 "The scope of anthropology." Current Anthropology 7:126-52.

1969 The Elementary Structures of Kinship. Boston: Beacon Press.

Manhattan Project

1979 "Up against the Wall Street Journal." Published handbook.

McCarthy, John D. and Mayer N. Zald

1973 The Trends of Social Movements in America: Professionalization and Resource Mobilization. Morristown, NJ: General Learning Press.

1977 "Resource mobilization and social movements." American Journal of Sociology 82:1212-41.

Mitchell, Robert Cameron

1981 "From elite quarrel to mass movement." Transactions/SOCIETY 18:76-84.

Nicholas, Ralph

1973 "Social and political movements." Annual Review of Anthropology 1:63-84.

Obserschall, Anthony D.

1973 Social Conflict and Social Movements. Englewood Cliffs, NJ: Prentice-Hall.

1978 "Theories of social conflict." Annual Review of Sociology 4:291-315.

Ormes, Ken

1979 "183 Clams arrested in RPV blockade." Clamshell Alliance News 3:1-6.

Rosenblith, Murray

1977 "Surrounded by acres of Clams." Win Magazine 13:4-10.

Sahlins, Marshall D.

1976 Culture and Practical Reason. Chicago: University of Chicago Press.

Schneider, David M.

1969 American Kinship: A Cultural Account. Englewood Cliffs, NJ: Prentice-Hall.

Smelser, Neil J.

1963 Theory of Collective Behavior. New York: Free Press.

1984 Sociology. Englewood Cliffs, NJ: Prentice-Hall.

Tracey, Sharon

1978 "Clams make waves at Seabrook." Clamshell Alliance News 3:1,8.

Useem, Bert

1980 "Solidarity model, breakdown model, and the Boston anti-busing movement." American Sociological Review 45:357-69.

Walsh, Edward

1978 "Mobilization theory vis-a-vis mobilization process: the case of the United Farm Workers' movement." Research in Social Movements, Conflicts and Change 1:155-77.

1981 "Resource mobilization and citizen protest in communities around Three Mile Island." Social Problems 29:1-21.

Walsh, Edward J. and Rex H. Warland

1983 "Social movement involvement in the wake of a nuclear accident: activists and free riders in the TMI area." American Sociological Review 48:764-80.

Wasserman, Harvey

1977 "The Clamshell Alliance: getting it together." The Progressive 42:14-18.

1979 Energy War: Reports from the Front. Westport, CT: Lawrence Hill \& Company.

Whitehead, Harriet

1974 "Reasonably fantastic: some perspectives on Scientology, science fiction, and occultism." Pp. 547-87 in Irving I. Zaretsky and Mark P. Leone (eds.), Religious Movements in Contemporary

Wolfe, Eric America. Princeton: Princeton University Press.

1977 "Our solidarity must embrace all people." PeaceWork 54:8-9.

Zald, Mayer

1980 "Issues in the theory of social movements." Current Perspectives in Social Theory 1:61-72. 